\title{
Design of Electric Vehicle Racing Car Chassis using Topology Optimization Method
}

\author{
Mohd Suffian bin Ab Razak ${ }^{1, *}$, Mohd Hudairee bin Hasim ${ }^{1}$, and Nor Azazi bin Ngatiman ${ }^{1}$ \\ ${ }^{1}$ Faculty of Engineering Technology (FTK), Technology Campus, Universiti Teknikal Malaysia \\ Melaka, Hang Tuah Jaya, 76100 Durian Tunggal, Melaka, Malaysia.
}

\begin{abstract}
The goal of this project is to improve the design of space frame chassis of electric vehicle which meet the rules and regulations of Formula Varsity (FV) Malaysia. The chassis was designed using topology optimization method and analyzed for its structural performance using various loading analyses and RULA assessment.
\end{abstract}

\section{Introduction}

FV Malaysia is a biennial racing car design competition organized by Universiti Teknikal Malaysia Melaka (UTeM), Malaysia, which is similar to the international Formula SAE. The electric vehicle category was introduced in 2015 to cultivate students' interest in electric vehicle technology. A number of initiatives has been applied in order to develop a light, fast, energy-efficient vehicle such as battery downsizing, use of advanced materials and design optimization to reduce excess weight. A study showed that by reducing 10 percent of the vehicle weight, energy efficiency could be increased by 5 to 8 percent. On top of that, reducing weight would improve the vehicle dynamics. Chassis, one of the most important components in the electric vehicle racing car must be designed optimally to reduce its weight, thus enhancing overall vehicle performance. All components and design must comply with the rules and regulation specified in the FV Malaysia technical specifications [1].

The objective of this project is to design an electric vehicle (EV) chassis for upcoming FV Malaysia competition that focus in weight reduction whilst not compromising on chassis strength and ergonomics (for the driver).

\section{Research methodology}

The research begins with material selection, generating conceptual design using topology optimization and preliminary Rapid Upper Limb Assessment (RULA). The design used ASTM 1 inch, A500 hollow steel with $1 \mathrm{~mm}$ wall thickness as it is cheaper than the higher grade A1085 and readily available in local market.

\footnotetext{
*Corresponding author: suffian@utem.edu.my
} 
Table 1. Material properties of the chassis

\begin{tabular}{|l|l|}
\hline Properties & ASTM A500 steel grade B \\
\hline Young's Modulus, E $[\mathrm{Mpa}]$ & $200 \mathrm{E}+03$ \\
\hline Poisson's Ratio, $v$ & 0.3 \\
\hline Material density, $\rho\left[\mathrm{t} / \mathrm{mm}^{3]}\right.$ & $7.85 \mathrm{E}-09$ \\
\hline
\end{tabular}

Chassis was initially designed in a monocoque body made of steel plate which is later converted to space frame. This novel method allows hollow structural section steel (HSS) to be modelled and simulated in shell meshes in order to distribute the load freely on a twodimensional space (plate). By using size optimization, the exact same size of hollow tube and plate (1-meter long, 1-inch width) is fixed on one side and $100 \mathrm{~N}$ force was applied on the other side to observe the maximum displacement and von mises stress, as shown in Figure 1 and 2. Plate thickness is varied using Hyperstudy in order to have similar performance with HSS tube in term of displacement and von mises stress. Optimization details are listed in Table 2.
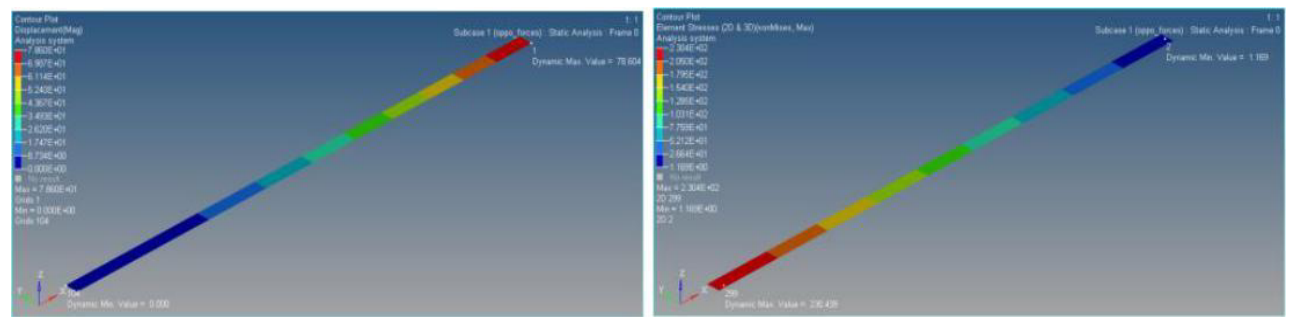

Fig. 1. Displacement of the plate (left) and von mises stress of the plate (right)
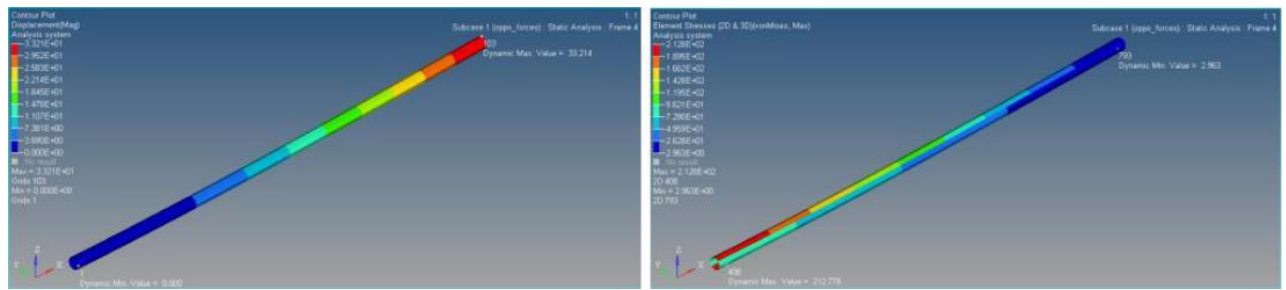

Fig. 2. Displacement of the tube (left) and von mises stress of the tube (right)

Table 2. Size optimization parameters

\begin{tabular}{|l|l|}
\hline Objective & Minimize mass \\
\hline Constraint & $\begin{array}{l}\text { Displacement plate } \leq \text { tube }(33.214 \mathrm{~mm}) \\
\text { Von mises stress plate } \leq \text { tube }(22.778 \mathrm{Mpa})\end{array}$ \\
\hline
\end{tabular}

Optimum plate thickness of $13.3034 \mathrm{~mm}$ obtained from Altair Hyperstudy software will be used for material thickness of the plate throughout this study.

Next, benchmarking on racing car chassis design was conducted and an Asian-size mannequin had been used to design a monocoque chassis which meet the FV Malaysia design regulations $[1,2]$.

The suspension mounting is located at the same location with 2015 EV model in order to maintain the suspension design and configurations. While the suspension mounting points and main hoop are set as non-design space, other area is set as design space where 
the material is allowed to be distributed within the defined space. The design of chassis is shown in Figure 3.
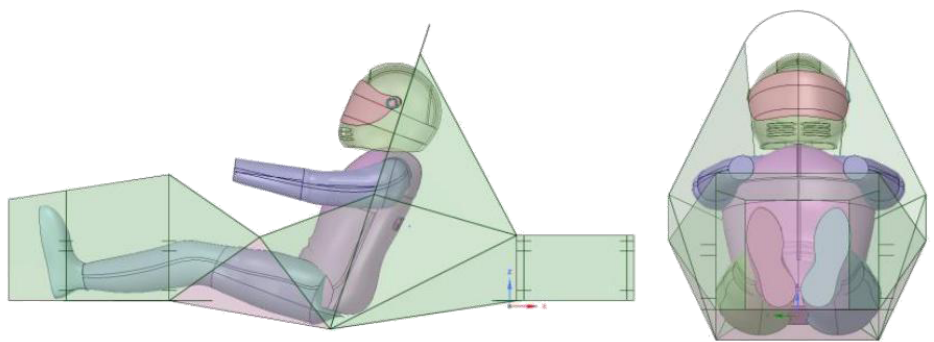

Fig. 3. Conceptual design of the chassis side view (left) and front view (right)

Symmetrical plane on Y-axis is applied at the centre. Support is assigned at rear mountings while combine load case for torsional (vertical, opposite direction), lateral (horizontal, same direction) loading and vertical bending load are applied at the front mounting and driver seat mounting [2]. Meshing setup and boundary conditions are shown in Figure 4.

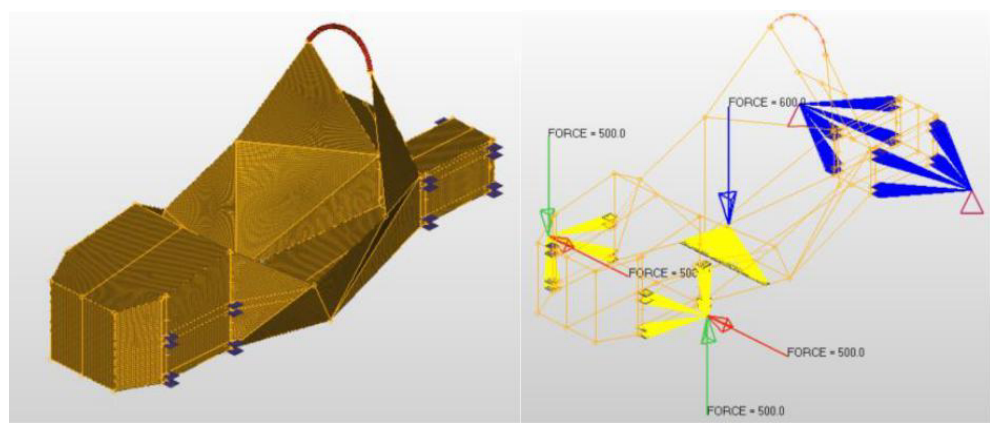

Fig. 4. Meshing setup (left) and boundary conditions (right)

Each force (Fn) acted on each mounting is calculated based on following equation:

$$
F n=\frac{(V m \cdot g)}{m n}
$$

Where $V m$ is gross vehicle mass, $g$ is gravitational acceleration and $m n$ is no. of suspension mountings. Altair Optistruct is a structural analysis solver in Hyperworks which allows user to develop a structurally efficient conceptual design that is right at the first time, thus reducing cost and shortening development time. Parameters for topology optimization are shown in Table 3. Generated optimized conceptual design (Figure 5) is then exported to CAD software in STL file format.

Table 3. Topology optimization optimization parameters

\begin{tabular}{|l|l|}
\hline Design Variable & Monocoque body (design space) \\
\hline Objective & Minimize weighted compliance \\
\hline Constraint & Maximum $30 \%$ of design space volume \\
\hline
\end{tabular}

Next, the chasis is designed with topology result as a reference in a hybrid modelling environment in CAD software, Ansys SpaceClaim. Direct modelling capability in SpaceClaim allows user to design a CAD model in the presence of STL file within same environment. 


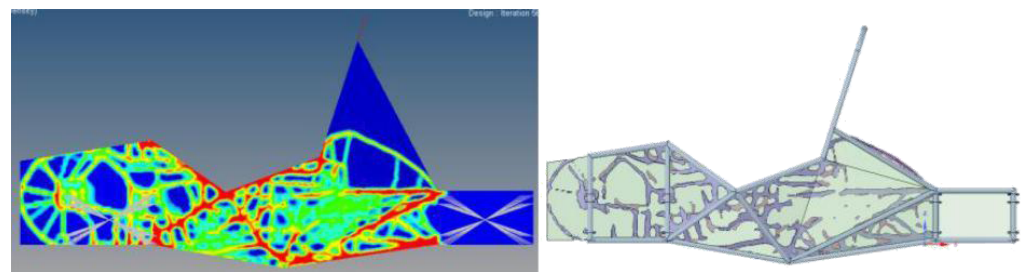

Fig. 5. Topology Optimization result in Altair Hyperview (left) and in Ansys SpaceClaim (right)

Topology optimization process will undergo few design iterations and optimization result will be easier to interpret compared to the initial design iteration.

Once the design is complete, the space frame chassis have to be analyzed for torsional, lateral and vertical loading. The performance is then compared to the $2015 \mathrm{EV}$ chassis.

Lastly, the space frame chassis design is evaluated based on FV Malaysia regulations and assessed on vehicle ergonomics while driving using Rapid Upper Limb Assessment (RULA). RULA assessed driver's comfort to avoid fatigue and muscle disorder. The correct driving posture, pedals, seat and steering location will be determined based on RULA assessment.

\section{Result and discussion}

Figure 6 shows the displacement and von mises stress result of the structure. Maximum deformations of $23.8 \mathrm{~mm}$ are at the front suspension mountings where the forces were applied. Since maximum von mises stress of $720 \mathrm{Mpa}$ are observed at seat mounting area, brackets should be installed to support excessive load. The chassis is considered safe as the driver's head is positioned $50 \mathrm{~mm}$ below the main hoop [3].

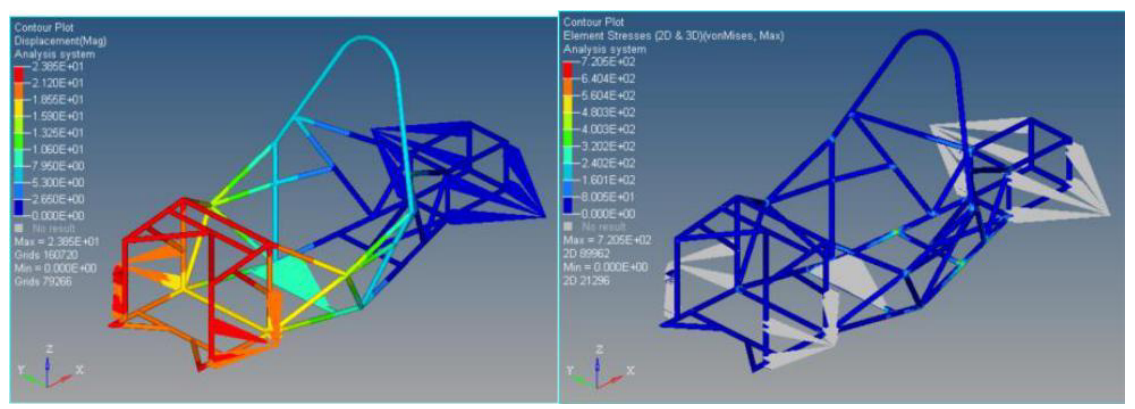

Fig. 6. Displacement result (left), von mises stress result (right) of the new model

The summary of improvement of the current design compared to the previous design is shown in Table 4. New EV chassis achieved mass and stress reduction, while structure deformation is similar to $2015 \mathrm{EV}$ model (Figure 7) with $1 \mathrm{~mm}$ difference.

Table 4. Comparison of performance

\begin{tabular}{|l|l|l|l|}
\hline Result & New model & 2015 EV model & Difference \\
\hline Mass (chassis only) $[\mathrm{kg}]$ & $\mathbf{1 6 . 8 7}$ & 18.97 & $-11.07 \%$ \\
\hline Max. displacement $[\mathrm{mm}]$ & 23.8 & $\mathbf{2 2 . 8}$ & $+4.38 \%$ \\
\hline Max. Von Mises Stress $[\mathrm{Mpa}]$ & $\mathbf{7 2 0}$ & 910 & $-21.74 \%$ \\
\hline
\end{tabular}




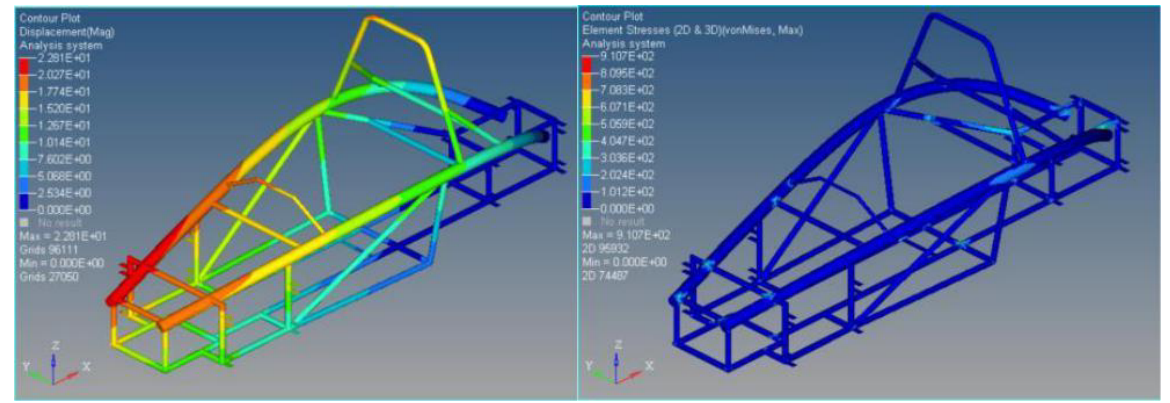

Fig. 7. Displacement result (left), von mises stress result (right) of 2015 EV model

To ensure comfort for the driver, posture plays an important role in terms of ergonomic during racing. RULA result in Figure 8 showed a final score of 2 (acceptable). This means the driver will not feel fatigue and will be comfortable around the upper-body.

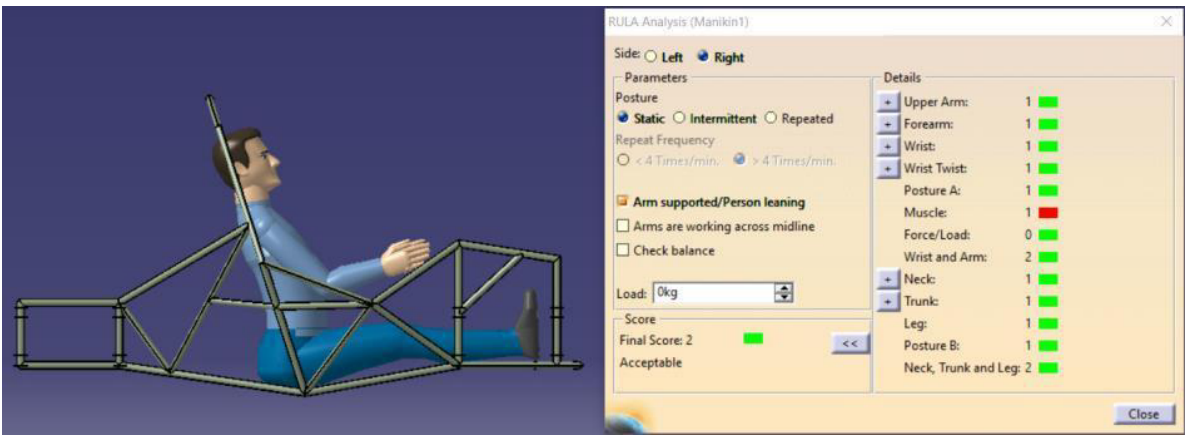

Fig. 8. RULA analysis

\section{Conclusions}

The objective to design an electric vehicle (EV) racing car chassis for FV Malaysia that focused in ergonomics and performance was achieved. The final score of RULA is 2 and the comfort level is within acceptable level. Topology optimization method can be applied to improve the vehicle performance.

The author would like to express appreciation to ACTIVE Research Group, Centre of Research on Energy (CARe) and Universiti Teknikal Malaysia Melaka (UTeM) for funding this project under PJP/2014/FTK(19C)/S01348.

\section{References}

1. Efa Riani, Ali. Vehicle Technical Specifications, (Universiti Teknikal Malaysia Melaka, 2015)

2. S. Kakria, D. Singh, CAE Analysis, SAE Technical Paper, 2015

3. M.H. Mat, A.R.A Ghani, Procedia Eng., 41, 1756 (2012) 